\title{
The Mechanisms of and the Interrelationship between
}

\section{Bile Acid and Chylomicron-Mediated Regulation of Hepatic Cholesterol Synthesis in the Liver of the Rat}

\author{
Flavio O. Nervi and John M. Dietschy, Department of Internal Medicine, \\ University of Texas Health Science Center at Dallas, Dallas, Texas 75235
}

A B S T RACT Hepatic cholesterol synthesis is controlled both by the size of the bile acid pool in the enterohepatic circulation and by the amount of cholesterol reaching the liver carried in chylomicron remnants. These studies were undertaken to examine how these two control mechanisms are interrelated. When the size of the pool was systematically varied, the logarithm of the rate of hepatic cholesterol synthesis varied in an inverse linear fashion with the size of the taurocholate pool between the limits of 0 and $60 \mathrm{mg}$ of bile acid per $100 \mathrm{~g}$ of body weight. The slope of this relationship gave the fractional inhibition of cholesterol synthesis associated with expansion of the taurocholate pool and was critically dependent upon the amount of cholesterol available for absorption from the gastrointestinal tract. Furthermore, the degree of inhibition of cholesterol synthesis in the liver seen with taurocholate feeding was reduced by partially blocking cholesterol absorption with $\beta$-sitosterol even though the bile acid pool was still markedly expanded. In rats with diversion of the intestinal lymph from the blood, a fivefold expansion of the taurocholate pool resulted in only slight suppression of the rate of hepatic cholesterol synthesis, and even this inhibition was shown to be attributable to small amounts of cholesterol absorbed through collateral lymphatic vessels and (or) to a fasting effect. Similarly, the infusion of either taurocholate or a combination of taurocholate and taurochenate into rats with no biliary or dietary cholesterol available for absorption caused no suppression of hepatic cholesterol synthesis. Finally, the effect of changes in the rate of bile acid synthesis on hepatic cholesterol synthesis

\footnotetext{
At the time of these studies Dr. Nervi was a postdoctoral fellow partially supported by a grant from the Catholic University of Chile. His present address is Departamento de Gastroenterologia, Universidad Catolica de Chile, Casilla 114-D, Santiago, Chile.

Received for publication 2 September 1977 and in revised form 1 December 1977.
}

was examined. The fractional inhibition of cholesterol synthesis found after administration of an amount of cholesterol sufficient to raise the hepatic cholesterol ester content by $1 \mathrm{mg} / \mathrm{g}$ equalled only -0.36 when bile acid synthesis was increased by biliary diversion but was -0.92 when bile acid synthesis was suppressed by bile acid feeding. It is concluded that $(a)$ bile acids are not direct effectors of the rate of hepatic cholesterol synthesis, $(b)$ most of the inhibitory activity seen with bile acid feeding is mediated through increased cholesterol absorption, and $(c)$ bile acids do have an intrahepatic effect in that they regulate hepatic cholesterol synthesis indirectly by altering the flow of cellular cholesterol to bile acids.

\section{INTRODUCTION}

It is known that all tissues are capable of at least some degree of de novo cholesterol synthesis. In addition, recent studies also have shown that many of these tissues have specialized membrane transport systems capable of taking up cholesterol carried in particular lipoprotein fractions from the surrounding medium. For example, tissues like lung, skin, kidney, and lymphocytes probably have a mechanism for membrane translocation of low density lipoproteins $(1,2)$ that is similar to or identical with that which has been described in the fibroblast in tissue culture (3). Certain endocrine glands such as adrenal gland and ovary also possess membrane mechanisms for rapid cellular uptake of high density lipoproteins $(1,4,5)$. Thus, in general, most tissues have two potential sources for cholesterol to meet their respective metabolic needs. However, in the presence of adequate levels of circulating high and low density lipoproteins, many of these tissues apparently will preferentially utilize the lipoprotein source of cholesterol and will suppress intracellular cholesterol synthesis. This type of reciprocal control readily explains why in animals, such as the rat and monkey, and in man, insofar as data are available, rates 
of cholesterol synthesis in most tissues are very low (6-9). The two major exceptions to this generalization are the liver and small bowel which, under the condition of a low intake of dietary sterols, synthesize cholesterol at high rates despite the fact that they are constantly perfused with relatively high levels of both high and low density lipoproteins (8-12). These two organs also are the sites of synthesis of the major classes of lipoproteins and, further, have been shown to be the major, if not the sole, sources for circulating serum cholesterol in intact animals and, presumably, in man (13-17).

Regulation of the rate of hepatic cholesterol synthesis is complex and is known to be influenced by many variables such as total caloric intake, stress, and even diurnal light cycling $(18,19)$. The two major regulatory mechanisms, however, of greatest physiological importance both have to do with maintenance of net sterol balance in the body; these include the two mechanisms responsible for adjustment of the rate of hepatic cholesterol synthesis to $(a)$ the amount of cholesterol entering the body through the gastrointestinal tract and $(b)$ the amount of sterol lost from the body as bile acids. There is little doubt that manipulation of either the amount of cholesterol in the diet or the size of the bile acid pool profoundly affects the rate of hepatic cholesterol synthesis $(8,9,18-22)$. There is considerable controversy, however, as to the exact mechanism(s) of how each of these effects is articulated. In earlier work we found no evidence that bile acids have a direct regulatory effect upon the rate-limiting enzyme, $\beta$-hydroxy$\beta$-methylglutaryl-CoA reductase (HMG CoA reductase), ${ }^{1}$ in the cholesterol bio-synthetic pathway and suggested that the principal effect of bile acid was to modulate the amount of cholesterol absorbed from the gastrointestinal tract (23). Subsequent work, however, has demonstrated that cholesterol synthesis in the liver is suppressed by bile acid feeding under circumstances where cholesterol absorption is partially, or perhaps completely, blocked by the administration of $\beta$-sitosterol (20) or by intestinal lymphatic diversion (24). Alternatively, hepatic cholesterol synthesis has been found to be enhanced after resection of the terminal ileum under circumstances where cholesterol absorption apparently is unchanged (25). These latter three studies again have raised the important possibility that bile acids may have a direct regulatory effect upon HMG CoA reductase within the liver cell.

The present detailed examination of this problem was undertaken because of the inherent importance of the identification of effectors of HMG CoA reductase in the liver and because of the current use of long term bile acid administration in man to alter biliary

${ }^{1}$ Abbreviation used in this paper: HMG CoA reductase, $\beta$-hydroxy- $\beta$-methylglutaryl-CoA reductase. cholesterol physiology $(26,27)$. If bile acids prove to be a specific inhibitor of HMG CoA reductase, then these substances might be useful in manipulating the rates of cholesterol synthesis and hepatic secretion of cholesterol into bile. Alternatively, if the effect of bile acids in mediated only through the mechanism of increased intestinal absorption, then prolonged administration of bile acid may prove detrimental to overall sterol balance in man.

\section{METHODS}

Animal preparations. The animals utilized in these studies were female, Sprague-Dawley-derived rats (Charles River Breeding Laboratories, Inc., Wilmington, Del.) purchased in the weight range of 150-170 g. Upon receipt, all animals were placed in an isolated animal room with automatic light cycling for 2-3 wk before use; the light phase began at 3 P.M. whereas the dark phase began at 3 A.M. During this time the animals were kept in individual metabolic cages and were fed $18 \mathrm{~g}$ of ground rat chow (Ralston Purina Co., St. Louis, Mo.) at 9 A.M. each day. In different experiments, as specifically outlined in the legends to the figures and tables, groups of animals received ground chow to which was added taurocholate, cholesterol, cholestyramine, or $\beta$-sitosterol in varying amounts. In one experiment ileal resection was performed as previously described (28), and the animals were then maintained in the light cycling room for 3 mo before use. In some experiments animals were operated upon and fitted with gastric and biliary or intestinal lymphatic cannulae (23). This type of animal preparation was fed a semisynthetic diet of casein and dextrin through the indwelling gastric cannulae at a rate of $1.0 \mathrm{ml} / \mathrm{h}$ throughout the $48-\mathrm{h}$ period of experimental observation; in some studies taurocholate or taurochenate was also dissolved in this diet (23). Thus, a number of different animal manipulations were utilized in these studies to explore specific points. However, in all studies the following precautions were observed: $(a)$ all animals were subjected to light cycling for 2-3 wk before use and were killed at a specific time in the light cycle; $(b)$ all experimental groups and their appropriate controls were fed isocaloric intakes of food and were subjected to the same experimental stress (19).

Chylomicron preparation and administration. In one set of studies (Fig. 5 and Table VI) chylomicrons were administered to groups of rats. These lipoproteins were obtained from donor animals fitted with intestinal lymphatic cannulae and fed a high cholesterol, high triglyceride diet (29). The lymph was collected in vessels containing EDTA and antibiotics and was centrifuged for $4 \mathrm{~h}$ at $22,000 \mathrm{rpm}$ in an SW 25.1 swinging bucket rotor (Beckman Instruments, Inc., Spinc. Div., Palo Alto, Calif.) (29). The lipoprotein layer was then resuspended and dialyzed against several changes of isotonic sodium chloride solution. Varying amounts of these chylomicrons were administered to test animals intravenously as a bolus at the mid-light point of the light cycle, and the animals were then killed $12 \mathrm{~h}$ later at the mid-dark point of the cycle $(29,30)$.

Incubation and assay procedures. Except for a few studies where the experiments were terminated at the mid-light point (9 P.M.), all rats were killed by decapitation at the mid-dark point ( 9 A.M.) of the light cycle. Liver slices were prepared and incubated in Krebs bicarbonate buffer containing $1 \mathrm{mM}$ $\left[1-{ }^{14} \mathrm{C}\right]$ octanoate as described in detail elsewhere (29-31). The incorporation of this substrate into digitonin precipitable sterols, $\mathrm{CO}_{2}$, and ketones was measured and, after correction for the specific activity of the intracellular acetyl CoA pool, 
these data were used to calculate the micromoles and nanomoles, respectively, of acetyl CoA units, i.e., $\mathrm{C}_{2}$ units, incorporated into $\mathrm{CO}_{2}$ and cholesterol per hour per gram wet weight of liver (31). Aliquots also were taken for determination of the total, free, and esterified cholesterol content of the liver; these data are expressed as the milligrams sterol per gram wet weight of liver (28-30). The pool of taurocholate present in each animal was measured by removing the entire small intestine. The intestine and its contents were cut into small pieces into ethanol containing a known quantity of radiolabeled taurocholate. The mixture was refluxed with vigorous mixing, and the taurocholate was isolated from the ethanolic supernate by repeated thin-layer chromatography in two different solvent systems. The specific activity of the bile acid was then determined, and the size of the taurocholate pool in the intestine was calculated on the basis of isotope dilution as previously described $(28,32)$. These values are reported as the milligrams of taurocholate in the small intestinal pool per $100 \mathrm{~g}$ of rat weight. Preliminary studies demonstrated that inclusion of the liver and biliary tract in the extraction mixture did not significantly alter the size of the measured taurocholate pool; thus, the taurocholate pool found in the small intestine when the animals were killed was assumed to equal the size of the physiologically important pool that was circulating through the enterohepatic circulation in the intact animal.

Mathematical treatment of data. Where appropriate, mean values for groups of data are given \pm 1 SEM. For correlating two variables linear regression curves were fitted to the data obtained from individual animals and have the usual form of $y=a+b x$. The values of $a$ and $b$ are given along with \pm 1 SD. As has been reported before for cholesterol feeding (33) and for lipoprotein injection $(23,29)$, the rate of hepatic cholesterol synthesis appears to vary in a log-linear fashion with the amount of cholesterol administered to the animals or with the level of hepatic cholesterol esters. Hence, in studies such as those shown in Figs. 2-5, the natural logarithm, ln, of the $\mathrm{C}_{2}$ flux into cholesterol was used for regression analysis of the relationship between the rate of cholesterol synthesis and the amount of cholesterol or bile acid administered or the level of hepatic cholesterol ester content. In this case $b$ can be considered as a constant giving the fractional inhibition of cholesterol synthesis produced by a given experimental manipulation.

\section{RESULTS}

To examine the mechanisms of bile acid mediated regulation of hepatic cholesterol synthesis and the relationship of this process to chylomicron mediated regulation, we have undertaken three different groups of studies. These include experiments $(a)$ to define the quantitative aspects of inhibition of hepatic cholesterol synthesis by bile acids, $(b)$ to characterize the dependency of this inhibitory capacity on the amount of cholesterol available for absorption, and $(c)$ to examine the effect of alterations in the enterohepatic circulation of bile acids on the hepatic uptake of chylomicron remnants and on the subsequent inhibition of hepatic cholesterol synthesis.

Characterization of the quantitative aspects of bile acid inhibition of hepatic cholesterol synthesis. This initial group of studies was undertaken to characterize bile acid-mediated inhibition of hepatic cholesterol synthesis under the carefully controlled conditions of light cycling and isocaloric food intake employed in these studies. Table I shows the effects of bile acid feeding on cholesterol synthesis at the mid-light and mid-dark phase of the light cycle. As seen in lines A and $\mathrm{C}$, the taurocholate pool $\cong 17 \mathrm{mg} / 100 \mathrm{~g}$ in control animals killed at either the mid-light or mid-dark point of the cycle even though, as expected, the rate of cholesterol synthesis was threefold higher during the dark phase. Feeding taurocholate for 5 days expanded the intestinal taurocholate pool to $\cong 36 \mathrm{mg} /$ $100 \mathrm{~g}$ (lines B and D), increased the level of hepatic total cholesterol, and suppressed the rate of cholesterol

TABLE I

Effect of Taurocholate Feeding on Hepatic Cholesterol Synthesis at the Mid-Light and Mid-Dark Phase of the Light Cycle

\begin{tabular}{lcccc}
\hline \multicolumn{1}{c}{$\begin{array}{c}\text { Experimental } \\
\text { group }\end{array}$} & $\begin{array}{c}\text { Taurocholate } \\
\text { pool }\end{array}$ & $\begin{array}{c}\text { Hepatic } \\
\text { cholesterol } \\
\text { content }\end{array}$ & & \multicolumn{2}{c}{$\mathrm{C}_{2}$ flux into- } \\
\cline { 5 - 6 } & $\mathrm{mg} / 100 \mathrm{~g}$ & $\mathrm{CO} / \mathrm{g}$ & Cholesterol \\
\hline & $17.2 \pm 1.0$ & $2.0 \pm 0.1$ & $\mu \mathrm{mol} / \mathrm{g} / \mathrm{h}$ & $\mathrm{nmol} / \mathrm{g} / \mathrm{h}$ \\
A. Mid-light control & $36.9 \pm 3.7^{*}$ & $2.9 \pm 0.3^{*}$ & $11.8 \pm 0.3$ & $238 \pm 74$ \\
B. Mid-light fed taurocholate & $17.7 \pm 0.9$ & $2.2 \pm 0.1$ & $11.3 \pm 0.9$ & $103 \pm 78$ \\
C. Mid-dark control & $35.8 \pm 3.6^{*}$ & $2.6 \pm 0.2^{*}$ & $11.0 \pm 0.3$ & $732 \pm 69$ \\
D. Mid-dark fed taurocholate & & & $10.9 \pm 0.3$ & $195 \pm 49^{*}$ \\
\hline
\end{tabular}

All animals were subjected to light cycling for $2 \mathrm{wk}$ and were then placed in individual metabolic cages and fed $18 \mathrm{~g}$ of ground rat chow each day at 9 A.M., the mid-dark phase of the light cycle, for an additional 5 days. During this time half of the rats received diet containing $0.3 \mathrm{~g}$ of taurocholate per $100 \mathrm{~g}$ of chow. Groups of animals were killed at either the mid-light or mid-dark phase of the light cycle and the size of the taurocholate pool in the small intestine, the content of cholesterol in the liver and the rate of cholesterol synthesis were measured. Each value represents the mean \pm 1 SEM for six animals in each group.

* Values that differ from the appropriate control values at the $P \leq 0.05$ level. 
synthesis in the animals killed at both the mid-light and mid-dark points of the cycle, although a diurnal rhythm in sterol synthesis was still evident. Because the rates of synthesis were higher and the degree of inhibition was greater in rats killed at the mid-dark point, most subsequent studies were undertaken during this period of the light cycle.

When the daily intake of taurocholate was fixed at a constant value there was a time-dependent change in several parameters of hepatic metabolism as shown in Fig. 1. In animals fed taurocholate over a 10-day period, the intestinal taurocholate pool progressively expanded from $\cong 15$ to $45 \mathrm{mg} / 100 \mathrm{~g}$ (panel A), and the cholesterol content of the liver increased from 1.9 to nearly $2.9 \mathrm{mg} / \mathrm{g}$. This increase was completely accounted for by an increase in the cholesterol ester content of the liver from 0.2 to $1.3 \mathrm{mg} / \mathrm{g}$ (panel C). Coincidental with these changes the rate of hepatic cholesterol synthesis decreased markedly from $\cong 900$ to 90 $\mathrm{nmol}$ per $\mathrm{g} / \mathrm{h}$ (panel A) under circumstances where there was no demonstrable change in the rate of $\mathrm{C}_{2}$
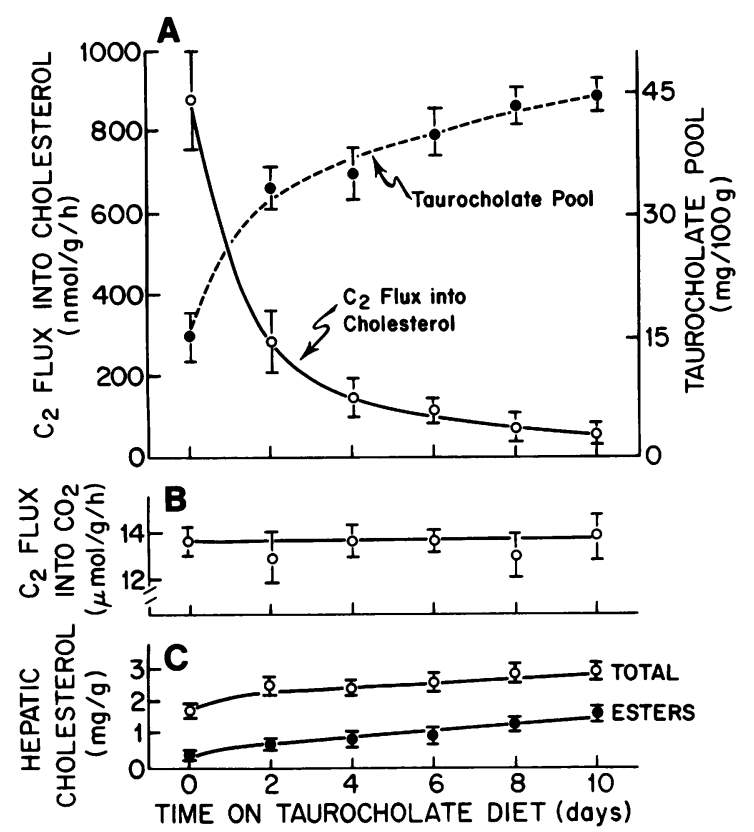

FIGURE 1 Rates of hepatic cholesterol synthesis as a function of the duration of taurocholate feeding. Animals were placed in individual metabolic cages in a light-cycling room and fed $18 \mathrm{~g}$ of ground rat chow each day at 9 A.M. After 10 days one group of rats was started on the same quantity of chow to which was added $0.5 \mathrm{~g}$ of taurocholate per $100 \mathrm{~g}$ of diet; other groups of animals were placed on this same diet every 2 days thereafter. 10 days later all groups of rats were killed at 9 A.M., and rates of $\mathrm{C}_{2}$ flux into cholesterol (panel $\mathrm{A}$ ) and $\mathrm{CO}_{2}$ (panel $\mathrm{B}$ ) were assayed in liver slices and the hepatic levels of total and esterified cholesterol (panel C) were measured. The size of the taurocholate pool present in the small intestine at the time the animals were killed also is shown in panel A. Each value represents the mean $\pm 1 \mathrm{SEM}$ for four animals in each group. flux into $\mathrm{CO}_{2}$ (panel B). Although these studies demonstrated a cumulative effect with respect to time when a constant amount of bile acid was fed, it was evident that most of the suppressive effect of taurocholate feeding was present within $48 \mathrm{~h}$. Because of this finding and because a number of complex, surgically prepared animal preparations could be most conveniently studied over a 2-day period, the time interval for most subsequent experiments was fixed at $48 \mathrm{~h}$.

Studies were next undertaken to examine the relationship between the magnitude of the metabolic effects and the amount of taurocholate fed over a 2-day interval. The results of these studies are shown in Fig. 2 where, it should be emphasized, the various parameters have been plotted against the size of the intestinal taurocholate pool found in each experimental group rather than against the amount of bile acid fed. In this manner it is possible to relate directly a given change in some aspect of hepatic metabolism to a given incremental increase in the size of the intestinal bile acid
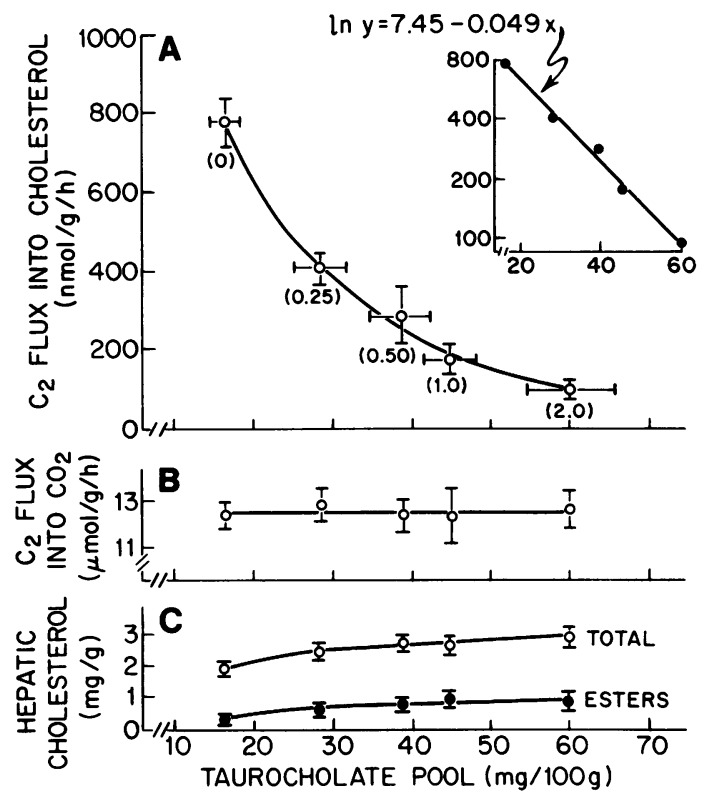

FIGURE 2 Rates of hepatic cholesterol synthesis as a function of the size of the taurocholate pool. Animals were subjected to light cycling and fed $18 \mathrm{~g}$ of ground rat chow each day at 9 A.M. for $2 \mathrm{wk}$. Then for $48 \mathrm{~h}$ before the animals were killed, groups of rats were fed $18 \mathrm{~g}$ of chow containing $0,0.25,0.50$, 1.0 , and $2.0 \mathrm{~g}$ of taurocholate per $100 \mathrm{~g}$ of diet (shown by the numbers in parenthesis in panel A). All groups were killed at 9 A.M., rates of $\mathrm{C}_{2}$ flux into cholesterol and $\mathrm{CO}_{2}$ were determined in liver slices, and the levels of hepatic total and esterified cholesterol were measured. Each of these values is plotted against the size of the taurocholate pool found in the small intestine when the animals were killed. Each point represents the mean \pm 1 SEM for four animals in each group. In panel $A$ \pm 1 SEM is shown for both the $C_{2}$ flux into cholesterol (vertical bars) and for the size of the taurocholate pool (horizontal bars) in each experimental group. 
pool. It is evident that feeding increasing amounts of taurocholate from 0 to $2.0 \mathrm{~g} / 100 \mathrm{~g}$ diet caused a fourfold increase in the intestinal taurocholate pool, nearly $90 \%$ suppression of hepatic cholesterol synthesis, and a fourfold increase in the hepatic ester content under circumstances where $\mathrm{CO}_{2}$ production by the liver was not changed. When replotted semilogarithmically, it also can be seen that cholesterol synthesis was suppressed as a linear function of the size of the bile acid pool; the slope of this relationship is such that the $\mathrm{C}_{2}$ flux into cholesterol decreased by a factor of 0.049 for each $1 \mathrm{mg} / 100 \mathrm{~g}$ that the bile acid pool was expanded or by a factor of approximately 0.78 for each doubling of the intestinal taurocholate pool. Furthermore, extrapolation of this curve to the $y$ axis when $x$ equals zero, i.e., where the taurocholate pool in the intestine equals zero, gives a theoretical rate of cholesterol synthesis of approximately $1,720 \mathrm{nmol}$ per $\mathrm{g} / \mathrm{h}$. In a separate experiment a mean rate of cholesterol synthesis of 1,770 $\pm 120 \mathrm{nmol}$ per $\mathrm{g} / \mathrm{h}$ was actually found when all of the bile acid pool was diverted away from the intestine over a 48-h period. Thus, it appears that the rate of hepatic cholesterol synthesis varies as a continuous log linear function of the size of the bile acid pool between the limits of zero and at least $60 \mathrm{mg} / 100 \mathrm{~g}$, an amount equal to approximately four times the normal taurocholate pool.

In the latter study it was tacitly assumed that the size of the intestinal bile acid pool was reflected by the amount of bile acid passing through the liver during its enterohepatic circulation. To demonstrate this directly, however, groups of four animals each were fed varying amounts of bile acid as described in the legend to Fig. 2, and after $48 \mathrm{~h}$ the common bile duct of each animal was cannulated, bile was collected for $1.0 \mathrm{~h}$, and hepatic secretory rates for taurocholate were determined. In these animals whose mean weight was 210 $\mathrm{g}$, the secretory rates varied from $7.2 \pm 0.5 \mathrm{mg} / \mathrm{h}$ in animals with an intestinal taurocholate pool of $16.0 \mathrm{mg} /$ $100 \mathrm{~g}$ to $17.7 \pm 1.2 \mathrm{mg} / \mathrm{h}$ in animals fed taurocholate to expand the pool to $45 \mathrm{mg} / 100 \mathrm{~g}$. From these secretory values it can be calculated that the number of cycles of the taurocholate pool was relatively constant and in the range of 4.5-5.1 per $24 \mathrm{~h}$, a finding which substantiates the assumption that changes in the intestinal taurocholate pool were associated with similar changes in the amount of taurocholate passing through the liver. Thus, on the basis of these findings, it is apparent that the relationship between the size of the taurocholate pool and the rate of hepatic cholesterol synthesis shown in Fig. 2 could be attributable $(a)$ to the effect of bile acid within the intestinal lumen, e.g., on cholesterol uptake into the mucosal cell, $(b)$ to an effect on some event within the intestinal mucosal cell, e.g., on chylomicron formation, or $(c)$ to an effect within the liver cell itself, e.g., direct inhibition of HMG CoA reductase.
The fourth experiment in this initial group of studies was designed to compare the effects of feeding equimolar amounts of taurocholate and cholesterol over a 48-h interval and to derive the mathematical relationships between the amount of sterol fed and their effect on cholesterol synthesis and cholesterol ester accumulation in the liver. As seen in panel A of Fig. 3 feeding $0-1,200 \mu \mathrm{mol}$ of taurocholate resulted in an increase in hepatic cholesterol esters of $0.0004 \mathrm{mg} / \mathrm{g}$ for each micromole of bile acid administered while the incremental increase in esters was nearly ninefold higher $(0.0035$ $\mathrm{mg} / \mathrm{g}$ per micromole fed) when equal amounts of cholesterol were fed (panel D). Although both taurocholate and cholesterol feeding inhibited hepatic cholesterol synthesis the fractional inhibition per micromole of sterol administered was 2.6-fold greater for cholesterol $(-0.0037$, panel E) than for bile acid $(-0.0014$, panel B). However, inasmuch as with cholesterol feeding the increase in cholesterol esters was out of proportion to the degree of inhibition of synthesis, the fractional inhibition of hepatic cholesterogenesis expressed per milligrams per gram of cholesterol esters present in the liver was threefold higher after taurocholate feeding $(-3.04$, panel $\mathrm{C})$ than after cholesterol feeding $(-1.04$, panel F).

The relationship between the inhibitory capacity of bile acid and the availability of cholesterol for absorption from the gastrointestinal tract. The second major group of studies was designed specifically to localize the site of action of bile acid in suppressing hepatic cholesterol synthesis to either the liver or the intestine. The initial experiment, the results of which are shown in Fig. 4 and Table II, demonstrates the relationship between the amount of cholesterol potentially available for absorption and the degree of inhibition produced by a given incremental increase in the size of the taurocholate pool. In this study four different groups of animals were utilized, each of which had varying amounts of cholesterol introduced into the gastrointestinal tract; groups A, B, and C were fed diets containing 90,24 , and $0 \mathrm{mg}$ of cholesterol, respectively, during the 48-h experimental period while an additional $7 \mathrm{mg}$ of cholesterol was assumed to enter the gastrointestinal tract in the bile $^{2}$ (column 1, Table II). Inasmuch as all cholesterol enters the body through the intestinal lymph, the cholesterol available for absorption is given as zero in the animals in group D which had intestinal lymphatic diversion. The question mark in Table II notes uncertainty in this regard, however, because the presence of collateral vessels in the

\footnotetext{
${ }^{2}$ This amount approximately equals the 48-h hepatic output of biliary cholesterol as estimated by cannulation of the common bile duct in similarly treated groups of animals and measurement of the cholesterol secretory rates over a 2-h interval.
} 

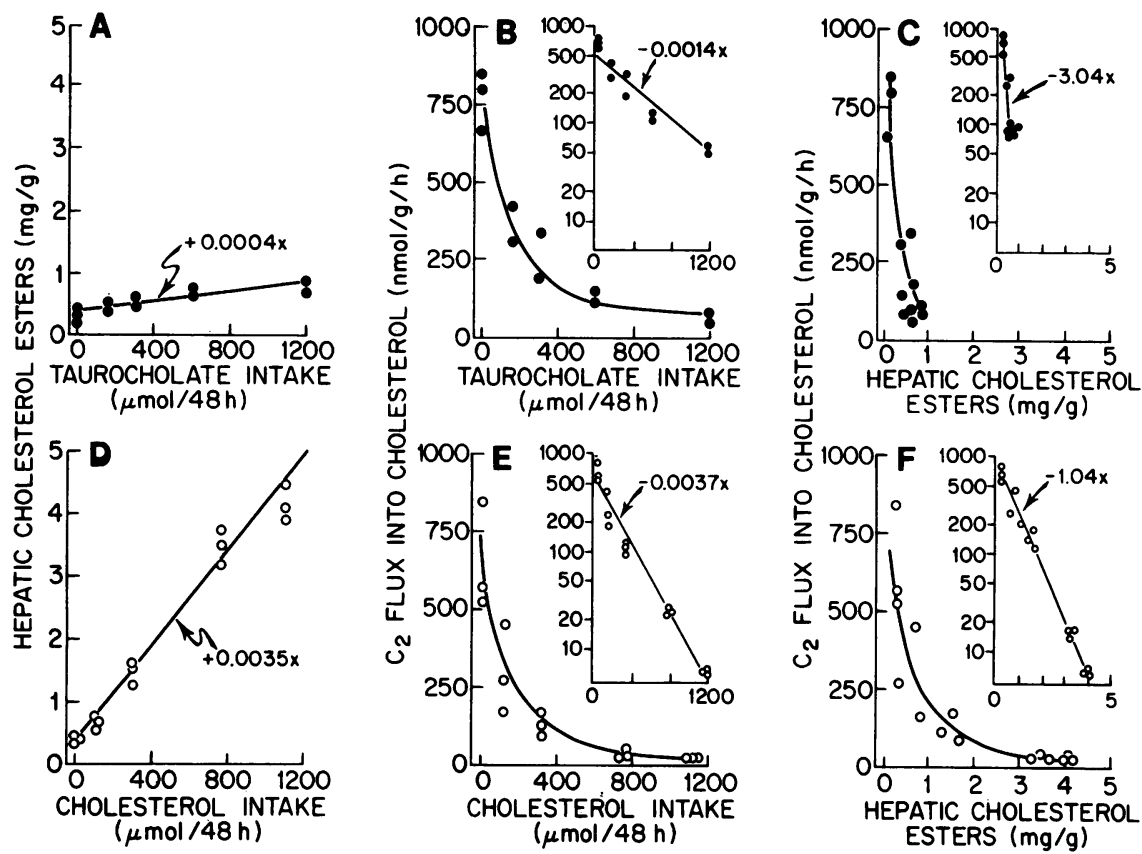

FIGURE 3 Comparison of the effects of feeding equimolar amounts of taurocholate (panels A, B, and $\mathrm{C}$ ) and cholesterol (panels D, E, and F) on rates of hepatic cholesterol synthesis. Animals were subjected to light cycling and were fed $18 \mathrm{~g}$ of ground rat chow each day at 9 A.M. for 2 wk. During the 48-h period before the rats were killed groups of animals were fed daily 18-g aliquots of diet containing varying amounts of either taurocholate or cholesterol. All groups were killed at 9 A.M., and rates of $\mathrm{C}_{2}$ flux into cholesterol and hepatic cholesterol ester levels were measured. In this figure the data are plotted to show the correlations between the level of hepatic cholesterol esters (panels A and D) or rates of cholesterol synthesis (panels B and E) and the micromoles of taurocholate or cholesterol ingested during the 48-h experimental period. The correlation of the level of hepatic cholesterol esters to the rate of cholesterol synthesis is shown in panels C and F. Data from individual animals are plotted and, in the case of the last two of these correlations, the linear regression curves fitted to the semilogarithmic plots of these data are shown. The slope of the fitted lines is given in each panel.

lymphatic circulation probably allows for a small, but unknown, quantity of cholesterol absorption as will be discussed in later experiments. The size of the taurocholate pool (column 2), the rate of hepatic cholesterol synthesis (column 3), and the level of cholesterol esters (column 4) in each of these types of animals when no taurocholate was added to the diet is also shown in Table II. As expected, the addition of cholesterol to the diet decreased the rate of synthesis but increased the level of hepatic cholesterol esters (group A vs. group B) while intestinal lymphatic diversion markedly enhanced the rate of sterol synthesis (group D vs. group C). It is not these values which are important, however, but rather the manner in which these parameters changed in response to systematic expansion of the taurocholate pool in each animal preparation. As is apparent in Fig. 4 the decrement in the rate of hepatic cholesterol synthesis and the increase in the level of hepatic cholesterol esters was directly proportional to the amount of cholesterol potentially available for absorption. These relationships are best seen by examin- ing the slopes of the regression lines (columns 5 and 6 , Table II) fitted to the individual data points presented in Fig. 4. It is apparent that the fractional inhibition of hepatic cholesterol synthesis decreased 12-fold, from -0.120 to -0.010 as the available cholesterol was decreased from 97 to $0 \mathrm{mg} / 48 \mathrm{~h}$, and there was an even greater decrease in the incremental change in hepatic cholesterol ester content. These findings strongly imply that most of the inhibition of hepatic cholesterol synthesis seen with expansion of the bile acid pool is directly related to an effect of this manipulation on increasing the movement of cholesterol from the intestine to the liver rather than to any direct effect of the bile acid on sterol synthesis within the hepatocyte.

This conclusion is supported by one additional type of experiment. Table III shows the results of a study in which groups of rats were fed a constant amount of cholesterol and tauorcholate to inhibit hepatic cholesterol synthesis. The addition of $\beta$-sitosterol, a drug which partially blocks cholesterol absorption, to the diet significantly reduced the degree of inhibition of 


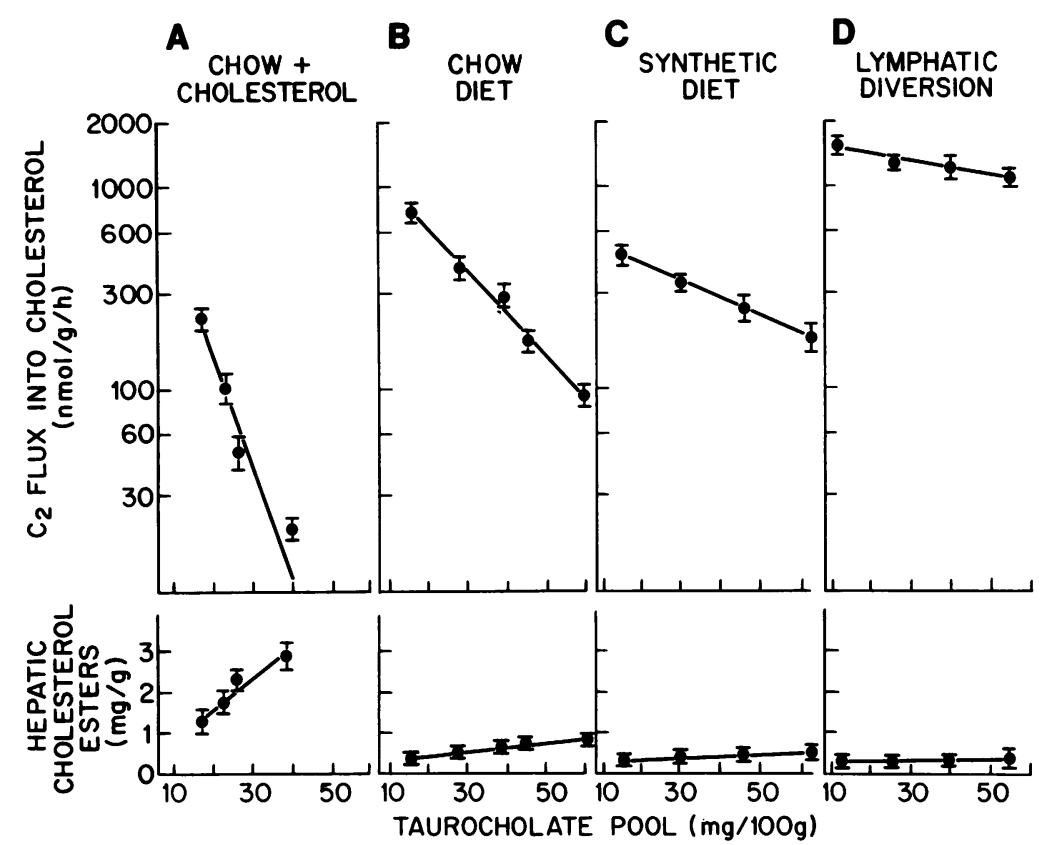

Figure 4 Dependency of the degree of inhibition of hepatic cholesterol synthesis by taurocholate feeding on the level of dietary cholesterol intake. All animals in these experiments were subjected to light cycling for $2 \mathrm{wk}$. Then for $48 \mathrm{~h}$ before the animals were killed groups of rats in panels $\mathrm{A}$ and $\mathrm{B}$ were fed $18 \mathrm{~g}$ of chow containing different amounts of taurocholate varying from 0 to $0.36 \mathrm{~g}$ daily. In addition, cholesterol was added to these diets so that $90 \mathrm{mg}$ of cholesterol was available for absorption during the 48-h period in the animals shown in panel A whereas $24 \mathrm{mg}$ was available in the diet in the experiment shown in panel $\mathrm{B}$. The animals in panels $C$ and $D$ were operated upon and fitted with indwelling gastric cannulae and, in panel $\mathrm{D}$, with intestinal lymphatic cannulae. Different groups of these animals were then infused at a rate of $1.0 \mathrm{ml} / \mathrm{h}$ with the synthetic diet containing from 0 to $4.0 \mathrm{mg}$ of taurocholate per milliliter continuously for $48 \mathrm{~h}$. At the end of this 48 -h experimental period all groups of animals were killed, and rates of hepatic cholesterol synthesis and the concentration of hepatic cholesterol esters were measured. In this figure these two parameters are plotted against the size of the taurocholate pool found in the small intestine when each animal was killed. Each point represents the mean \pm 1 SEM for four to six animals in each group.

TABLE II

Degree of Inhibition of Hepatic Cholesterol Synthesis by Taurocholate Feeding as a Function of the Amount of Cholesterol Available for Intestinal Absorption

\begin{tabular}{|c|c|c|c|c|c|c|}
\hline \multirow[b]{2}{*}{ Experimental group } & \multirow[b]{2}{*}{$\begin{array}{c}\text { Cholesterol } \\
\text { available for } \\
\text { absorption }\end{array}$} & \multicolumn{3}{|c|}{ Values in animals receiving no taurocholate } & \multirow{2}{*}{$\begin{array}{l}\text { Fractional } \\
\text { inhibition of } \\
\text { cholesterol } \\
\text { synthesis }\end{array}$} & \multirow[b]{2}{*}{$\begin{array}{l}\text { Increase in hepatic } \\
\text { cholesterol esters }\end{array}$} \\
\hline & & $\begin{array}{c}\text { Taurocholate } \\
\text { pool }\end{array}$ & $\begin{array}{l}\mathrm{C}_{2} \text { flux into } \\
\text { cholesterol }\end{array}$ & $\begin{array}{l}\text { Hepatic } \\
\text { cholesterol } \\
\text { esters }\end{array}$ & & \\
\hline & $m g / 48 h$ & $m g / 100 \mathrm{~g}$ & nmol/g/h & $m g / g$ & $(m g / 100 g)^{-1}$ & $(m g / g) \cdot(m g / 100 g)^{-1}$ \\
\hline A. Chow + cholesterol & $90(7)$ & $17.2 \pm 3.0$ & $223 \pm 15$ & $1.09 \pm 0.30$ & $-0.120^{*}$ & $+0.087^{*}$ \\
\hline B. Chow diet & $24(7)$ & $16.3 \pm 2.0$ & $780 \pm 50$ & $0.19 \pm 0.03$ & -0.052 & +0.013 \\
\hline C. Synthetic diet & $0(7)$ & $14.8 \pm 1.9$ & $480 \pm 52$ & $0.18 \pm 0.04$ & $-0.021 *$ & $+0.006^{*}$ \\
\hline D. Lymphatic diversion & $0(? 0)$ & $13.2 \pm 2.5$ & $1,628 \pm 270$ & $0.18 \pm 0.02$ & $-0.010^{*}$ & $+0.002^{*}$ \\
\hline
\end{tabular}

These data were derived by fitting linear regression curves to the individual data points obtained in the animals in the experiments shown in Fig. 4. The data in Column 1 give the amount of cholesterol available in each experiment for intestinal absorption: the first number shows the amount actually fed in each type of diet; the number in parenthesis represents the amount of cholesterol presumed to enter the intestine in the bile. The values given in columns 2,3 , and 4 were obtained in the animals not receiving exogenous taurocholate. The data in column 5 give the fractional inhibition constants for the rate of cholesterol synthesis while those in column 6 show the incremental increases in hepatic cholesterol esters associated with an increase in the taurocholate pool by $1 \mathrm{mg}$ per $100 \mathrm{~g}$ rat.

* Values that differ from the control values (group B) at the $P \leq 0.05$ level. 
TABLE III

Effect of $\beta$-Sitosterol on the Degree of Inhibition of Hepatic Cholesterol Synthesis Produced by Taurocholate Feeding

\begin{tabular}{|c|c|c|c|}
\hline \multirow[b]{2}{*}{ Experimental group } & \multirow{2}{*}{$\begin{array}{l}\text { Taurocholate } \\
\text { pool }\end{array}$} & \multicolumn{2}{|c|}{$\mathrm{C}_{2}$ flux into- } \\
\hline & & $\mathrm{CO}_{2}$ & Cholesterol \\
\hline & $m g / 100 \mathrm{~g}$ & $\mu \mathrm{mol} / \mathrm{g} / \mathrm{h}$ & $n m o l / g / h$ \\
\hline \multicolumn{4}{|l|}{$\begin{array}{l}\text { A. Animals killed at } \\
\text { mid-light point }\end{array}$} \\
\hline Control & $17.3 \pm 3.8$ & $10.7 \pm 0.4$ & $188 \pm 30$ \\
\hline Taurocholate & $43.6 \pm 1.4^{*}$ & $10.4 \pm 0.7$ & $104 \pm 23^{*}$ \\
\hline $\begin{array}{l}\text { Taurocholate } \\
\text { and }\end{array}$ & & & \\
\hline$\beta$-sitosterol & $35.7 \pm 2.9 *$ & $9.7 \pm 0.7$ & $207 \pm 37$ \\
\hline \multicolumn{4}{|l|}{$\begin{array}{l}\text { B. Animals killed at } \\
\text { mid-dark point }\end{array}$} \\
\hline Control & $16.8 \pm 0.7$ & $11.2 \pm 0.4$ & $456 \pm 79$ \\
\hline Taurocholate & $36.5 \pm 4.9 *$ & $12.3 \pm 0.5$ & $182 \pm 65^{*}$ \\
\hline \multicolumn{4}{|l|}{ Taurocholate } \\
\hline$\beta$-sitosterol & $38.4 \pm 3.0^{*}$ & $9.8 \pm 0.4$ & $333 \pm 56$ \\
\hline
\end{tabular}

All animals were subjected to light cycling for $2 \mathrm{wk}$ and were then placed in individual metabolic cages for 3 days during which time different groups were fed $18 \mathrm{~g}$ of ground rat chow daily (control) or this same amount of food containing taurocholate $(0.5 \mathrm{~g}$ per $100 \mathrm{~g}$ diet $)$ or taurocholate $(0.5 \mathrm{~g}$ per $100 \mathrm{~g}$ diet) and $\beta$-sitosterol $(5 \mathrm{~g}$ per $100 \mathrm{~g}$ diet). Animals from these three groups were then killed at either the mid-light or mid-dark phase of the light cycle and the size of the taurocholate pool in the small intestine and the rates of hepatic cholesterol synthesis were measured. Each value represents the mean \pm 1 SEM for four or five animals in each group.

* Values that differ from the appropriate control values at the $P \leq 0.05$ level.

cholesterol synthesis produced by bile acid feeding at either the mid-light or the mid-dark point of the light cycle even though both groups manifested essentially the same increases in the size of the intestinal taurocholate pool.

Although these various results all support the view that most of the inhibitory effect of bile acid is mediated through increased cholesterol absorption, the question still remains as to whether bile acid has any direct inhibitory effect on the rate of hepatic cholesterol synthesis. This uncertainty derives principally from the observation shown in panel D of Fig. 4 that there was still a small amount of residual inhibition seen in the animals with intestinal lymphatic diversion when the taurocholate pool was expanded nearly fivefold: this observation is essentially identical to that previously reported by Hamprecht et al. (24). To obtain more definitive data in this critical group of animals, 24 more rats were prepared with intestinal lymphatic cannulae, and half of these were infused with taurocholate. As seen in column 5 of Table IV, diversion of the intestinal lymph enhanced $\mathrm{C}_{2}$ flux into cholesterol threefold, from 534 to $1628 \mathrm{nmol}$ per g/h. Infusion of taurocholate into animals with lymphatic diversion (group C) increased the taurocholate pool nearly fivefold, from 10.5 to 48.1 $\mathrm{mg} / 100 \mathrm{~g}$, but suppressed cholesterol synthesis only $32 \%$, from 1,628 to $1,105 \mathrm{nmol}$ per $\mathrm{g} / \mathrm{h}$. Although such a result might suggest a minor direct inhibitory effect of bile acid within the liver, two other observations were made in this study that make even this conclusion unlikely. First, at surgery it was apparent that small collateral lymphatic vessels were always present beside the main intestinal lymphatic duct so that it was likely that even this small amount of inhibition could be accounted for by small amounts of cholesterol reaching the liver from the intestine. From the quantitative relationship shown in panel $\mathrm{C}$ of Fig. 3 between the degree of inhibition of cholesterol synthesis and the level of hepatic cholesterol esters achieved with taurocholate feeding, it can be calculated that the observed $32 \%$ inhibition of cholesterol synthesis could be accounted for by the absorption of a small amount of cholesterol that increased the cholesterol ester content of the liver by only $0.13 \mathrm{mg} / \mathrm{g}$. It is important, therefore, that the taurocholate-infused animals manifested an increase in the cholesterol ester content of the liver of this order of magnitude (column 2). Furthermore, when trace quantities of radiolabeled cholesterol were introduced into the stomach of these animals, irregular amounts varying from $1 \%$ to $12 \%$ of the administered dose could be recovered in the liver $12 \mathrm{~h}$ later. Second, it was found that the volume of lymph flow was significantly higher in the animals receiving taurocholate than in those which did not and, further, this lymph contained $\cong 45 \%$ more protein and $67 \%$ more lipid than the lymph from the group of animals with the normal taurocholate pool. Thus, even though both groups were receiving the fat-free semisynthetic diet, it was apparent that the animals receiving taurocholate were not in caloric balance with the animals not receiving bile acid (group B). That this former group was partially fasted is supported by the observation that hepatic ketone synthesis, a sensitive indicator of caloric deprivation, was significantly elevated in the taurocholate infused animals (column 3). Thus, because of the presence of lymphatic collaterals and because of the possibility of a relative fasting effect, even the slight degree of inhibition seen in studies such as these cannot be taken as evidence for a direct suppressive effect of bile acids on heating cholesterol synthesis.

This conclusion was further supported by one final set of studies in this group where bile acid was removed from, rather than added to, the enterohepatic circulation. As seen in Table $\mathrm{V}$ in animals receiving a cholesterol-free diet, the diversion of both bile acid and biliary cholesterol from the gastrointestinal tract resulted in a 2.6-fold increase in the rate of cholesterol synthesis 
TABLE IV

Effect of Feeding Taurocholate on Hepatic Cholesterol Synthesis in Animals with Intestinal Lymphatic Diversion

\begin{tabular}{lccccc}
\hline & & Tepatic & & \multicolumn{2}{c}{$\mathrm{C}_{2}$ flux into- } \\
\cline { 4 - 6 } \multicolumn{1}{c}{ Experimental group } & pool & $\begin{array}{c}\text { Tholesterol } \\
\text { esters }\end{array}$ & $\begin{array}{c}\text { Total ketone } \\
\text { synthesis }\end{array}$ & $\mathrm{CO}_{2}$ & Cholesterol \\
\hline & $m g / 100 \mathrm{~g}$ & $m g / g$ & $\mu m o l / g / h$ & $\mu m o l / g / h$ & $n m o l / g / h$ \\
A. Control & $13.5 \pm 3.0$ & $0.19 \pm 0.03$ & $7.9 \pm 1.0$ & $10.9 \pm 0.8$ & $534 \pm 47$ \\
B. Lymphatic diversion & $10.5 \pm 1.3$ & $0.16 \pm 0.02$ & $8.4 \pm 0.2$ & $10.5 \pm 1.3$ & $1,628 \pm 69$ \\
C. Lymphatic diversion fed taurocholate & $48.1 \pm 8.0^{*}$ & $0.27 \pm 0.04^{*}$ & $11.6 \pm 0.4^{*}$ & $11.2 \pm 0.7$ & $1,105 \pm 35^{*}$ \\
\hline
\end{tabular}

All animals in this study were subjected to light cycling for 2 weeks and then operated upon and fitted with an indwelling gastric cannula (group A) or with a gastric cannula and an intestinal lymphatic cannula (groups $\mathrm{B}$ and $\mathrm{C}$ ). After completion of the surgery all animals were administered the semisynthetic diet through the gastric cannula at a rate of $1.0 \mathrm{ml} / \mathrm{h}$ for $48 \mathrm{~h}$; in the animals in group C this diet also contained $2.0 \mathrm{mg}$ of taurocholate per milliliter. After $48 \mathrm{~h}$ all rats were killed, the small intestinal taurocholate pool and level of hepatic cholesterol esters were measured, and rates of ketone, $\mathrm{CO}_{2}$, and cholesterol synthesis were assayed. Each value represents the mean \pm 1 SEM for 6-12 animals in each group.

* Values in group C that differ from those in group B at the $\mathrm{P} \leq 0.05$ level.

by the liver. When the flow of bile acid, but not cholesterol, from the gastrointestinal tract to the liver was restored by the infusion of either taurocholate alone (group C) or taurocholate plus taurochenate (group D), there was no significant suppression of sterol synthesis by the liver. In a separate experiment acute cannulation of the common bile duct in control rats (group A) revealed an average hepatic secretory rate of taurocholate of $7.1 \mathrm{mg} / \mathrm{h}$ and of total bile acids of $10.9 \mathrm{mg} / \mathrm{h}$. Thus, the amounts of bile acid infused into the animals with biliary diversion and essentially quantitatively recovered in the biliary outflow (from 17.5 to $24.0 \mathrm{mg} / \mathrm{h}$ ) actually exceeded the normal flow of bile acids through the liver by a factor of 1.6-2.6. In spite of this, however, in the absence of either dietary or biliary cholesterol in the intestine, restoration of the enterohepatic cir- culation of bile acids caused no detectable suppression of the hepatic cholesterol synthesis.

Effect of altering the enterohepatic circulation of bile acids on the uptake of chylomicron-cholesterol and on the subsequent inhibition of hepatic cholesterol synthesis. Because the preceding studies demonstrated that bile acid had no direct suppressive effect on hepatic cholesterol synthesis, a third group of investigations was undertaken to examine the possibility that the amount of bile acid fluxing through the liver might indirectly alter the rate of hepatic cholesterol synthesis by altering the rate of chylomicron remnant uptake and (or) the magnitude of suppression of sterol synthesis induced by the entry of cholesterol into the hepatocyte. In this experiment two groups of animals, one a control group and the second fed cholestyramine

TABLE V

Effect of Taurocholate and Taurochenate Infusion on Hepatic Cholesterol Synthesis in Dark-Adapted Rats with Biliary Diversion

\begin{tabular}{|c|c|c|c|c|}
\hline \multirow[b]{2}{*}{ Experimental group } & \multirow{2}{*}{$\begin{array}{c}\text { Taurocholate } \\
\text { pool }\end{array}$} & \multirow{2}{*}{$\begin{array}{c}\text { Hepatic } \\
\text { cholesterol } \\
\text { esters }\end{array}$} & \multicolumn{2}{|c|}{$\mathrm{C}_{2}$ flux into- } \\
\hline & & & $\mathrm{CO}_{2}$ & Cholesterol \\
\hline & $m g / 100 \mathrm{~g}$ & $m g / g$ & $\mu \mathrm{mol} / \mathrm{g} / \mathrm{h}$ & nmol/g/h \\
\hline A. Intact control & $14.8 \pm 1.9$ & $0.19 \pm 0.04$ & $10.2 \pm 0.4$ & $480 \pm 52$ \\
\hline B. Biliary diversion & $0.2 \pm 0.1$ & $0.15 \pm 0.03$ & $9.8 \pm 0.4$ & $1,235 \pm 108$ \\
\hline C. Biliary diversion + taurocholate & $9.8 \pm 0.9^{*}$ & $0.16 \pm 0.02$ & $9.5 \pm 0.7$ & $1,146 \pm 122$ \\
\hline D. Biliary diversion + taurocholate and taurochenate & $11.7 \pm 1.0^{*}$ & $0.19 \pm 0.02$ & $11.0 \pm 0.5$ & $1,120 \pm 160$ \\
\hline
\end{tabular}

All animals in this study were subjected to light cycling for 2 wk and were then operated upon and fitted with indwelling gastric cannulae. In addition, the animals in groups B, C, and D also had an indwelling biliary cannula. All groups were administered the semisynthetic diet at a rate of $1.0 \mathrm{ml} / \mathrm{h}$ for $48 \mathrm{~h}$. This diet also contained taurocholate $(20 \mathrm{mg} / \mathrm{ml})$ in group $\mathrm{C}$ and taurocholate $(15 \mathrm{mg} / \mathrm{ml})$ and taurochenate $(5 \mathrm{mg} / \mathrm{ml})$ in group D. After $48 \mathrm{~h}$ the animals were killed, and the size of the bile acid pool and rates of cholesterol synthesis were measured. Each point represents the mean $\pm 1 \mathrm{SEM}$ for determinations in five animals in each group.

* Values in groups $C$ and D that differ from those in group B at the $P \leq 0.05$ level. 
to interrupt partially the enterohepatic circulation of bile acids, were administered intravenously a bolus of chylomicrons containing varying amounts of cholesterol $12 \mathrm{~h}$ before the time the animals were killed. Rates of cholesterol synthesis and levels of hepatic cholesterol esters were then assayed. As seen in panel A of Fig. 5, the uptake of chylomicron cholesterol, as manifest by the level of hepatic cholesterol esters, was essentially the same in the two groups and equaled 0.090 and $0.114 \mathrm{mg} / \mathrm{g}$ for each milligram of chylomicron cholesterol administered to the control and cholestyramine treated rats, respectively. While the rates of hepatic cholesterol synthesis were displaced upward in the cholestyramine-treated animals, as seen in panel $\mathrm{B}$, the fractional inhibition constants for cholesterol synthesis were similar in the two groups equaling -0.074 and -0.067 in the control and treated rats, respectively. When the rates of synthesis were plotted against the cholesterol ester level the two regression curves diverged slightly, as seen in panel $\mathrm{C}$, indicating that the fractional inhibition constant was slightly lower in the cholestyramine-treated animals $(-0.51)$ than in the control group $(-0.64)$.

Using this same protocol a series of similar investigations were undertaken in which the size of the bile acid pool was either increased or decreased over a variable period of time. As summarized in Table VI, in addition to cholestyramine feeding for 7 days (group B), more complete interruption of the enterohepatic circulation was accomplished by either biliary diversion for $48 \mathrm{~h}$ (group A) or by total ileal resection for $3 \mathrm{mo}$ (group C). These manipulations all resulted in a threefold increase in hepatic cholesterol synthesis in animals receiving no lipoproteins intravenously (column 2 ). The increase in the cholesterol ester content of the liver (column 3) and the fractional inhibition constants
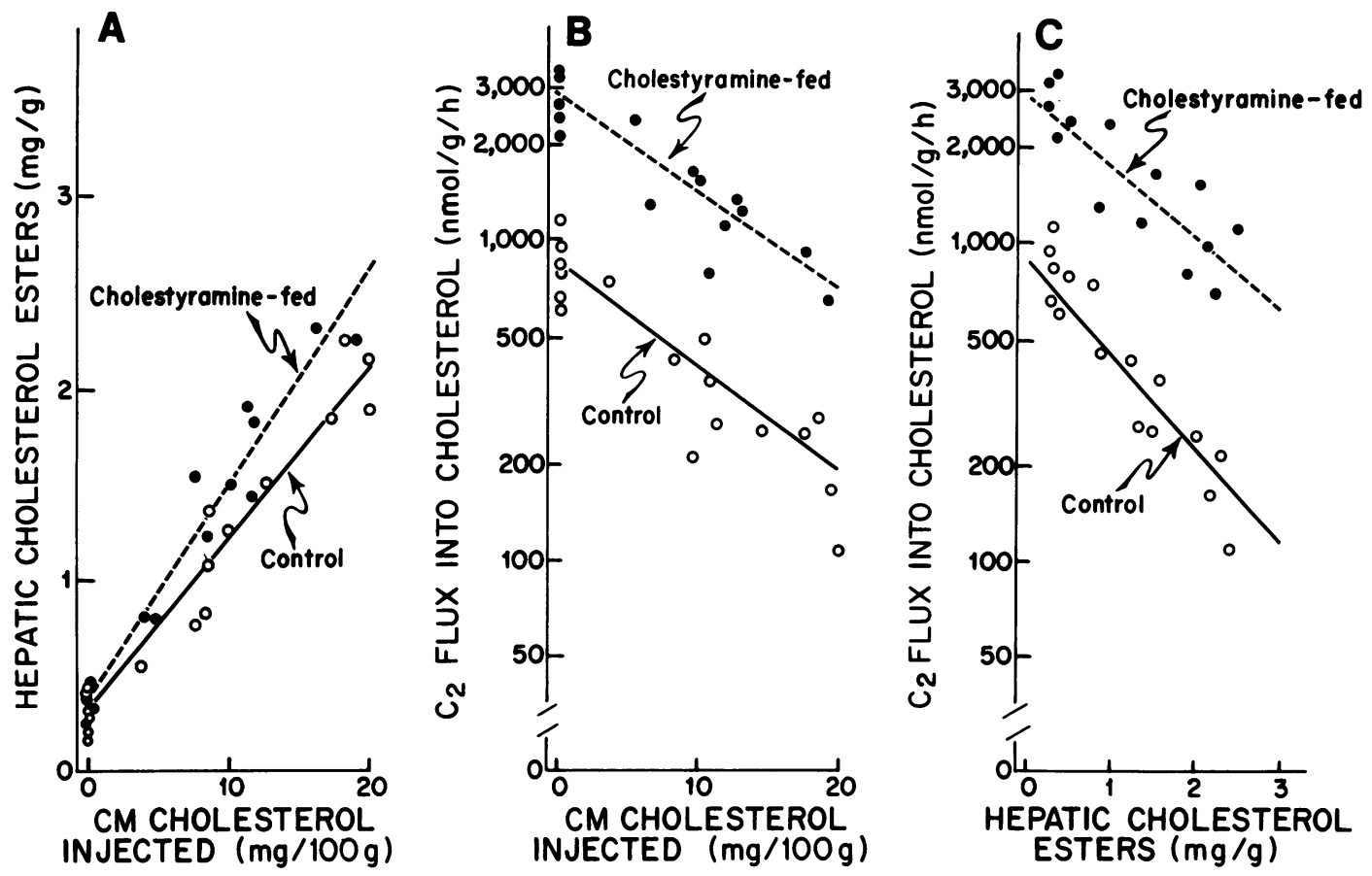

FIGURE 5 The relationship of the level of hepatic cholesterol esters and the rate of hepatic cholesterol synthesis to the amount of chylomicron cholesterol injected into control and cholestyramine-fed rats. All animals in this study were subjected to light-cycling for 3 wk. During the last week of cycling each animal was fed $18 \mathrm{~g}$ of ground rat chow daily; half of the animals received chow to which $1 \mathrm{~g}$ of cholestyramine resin was added per $100 \mathrm{~g}$ of diet. At the end of this time each animal was injected intravenously with varying amounts of chylomicrons (CM) during the mid-light phase of the light cycle and was then killed $12 \mathrm{~h}$ later at the mid-dark phase. The amount of chylomicron cholesterol injected is expressed as the mg of cholesterol administered per $100 \mathrm{~g}$ rat weight. In panel A, the level of hepatic cholesterol esters found when the animals were killed is plotted as a function of the amount of chylomicron cholesterol injected while in panels $B$ and $C$ the rates of hepatic cholesterol synthesis are plotted semilogarithmically against the amount of chylomicron cholesterol injected and the level of hepatic cholesterol esters, respectively. Each point represents the result obtained in an individual animal. The linear regression curves were fitted to the data by the method of least squares; the slopes of these regression lines are given in Table VI, experimental group B. 
TABLE VI

Effect of the Size of the Bile Acid Pool on the Rates of Hepatic Uptake of Chylomicron Cholesterol and on Suppression of Hepatic Cholesterol Synthesis

\begin{tabular}{|c|c|c|c|c|c|}
\hline \multirow[b]{2}{*}{ Experimental group } & & \multirow[b]{2}{*}{$\begin{array}{l}\mathrm{C}_{2} \text { flux into } \\
\text { cholesterol }\end{array}$} & \multirow{2}{*}{$\begin{array}{c}\begin{array}{c}\text { Hepatic } \\
\text { cholesterol } \\
\text { esters }\end{array} \\
\begin{array}{c}\text { Cholesterol- } \\
\text { injected }\end{array}\end{array}$} & \multicolumn{2}{|c|}{ ln Cholesterol synthesis } \\
\hline & & & & $\begin{array}{l}\text { Cholesterol- } \\
\text { injected }\end{array}$ & $\begin{array}{c}\text { Hepatic } \\
\text { cholesterol } \\
\text { esters }\end{array}$ \\
\hline & $n$ & nmol/g/h & $(m g / g) \cdot(m g / 100 g)^{-1}$ & $(m g / 100 g)^{-1}$ & $(m g / g)^{-1}$ \\
\hline \multicolumn{6}{|c|}{ A. Biliary diversion $(48 \mathrm{~h})$} \\
\hline Control & 15 & $608 \pm 139$ & $+0.116 \pm 0.017$ & $-0.089 \pm 0.024$ & $-0.72 \pm 0.11$ \\
\hline Diversion & 14 & $1,851 \pm 251$ & $+0.162 \pm 0.020$ & $-0.079 \pm 0.030$ & $-0.37 \pm 0.20$ \\
\hline \multicolumn{6}{|c|}{ B. Cholestyramine-fed (7 days) } \\
\hline Control & 17 & $855 \pm 195$ & $+0.090 \pm 0.006$ & $-0.074 \pm 0.026$ & $-0.64 \pm 0.30$ \\
\hline Cholestyramine & 15 & $2,811 \pm 277$ & $+0.114 \pm 0.014$ & $-0.067 \pm 0.012$ & $-0.51 \pm 0.09$ \\
\hline \multicolumn{6}{|l|}{ C. Ileal resection (3 mo) } \\
\hline Control & 9 & $686 \pm 97$ & $+0.132 \pm 0.012$ & $-0.071 \pm 0.009$ & $-0.69 \pm 0.25$ \\
\hline Resection & 11 & $1,881 \pm 196$ & $+0.176 \pm 0.026$ & $-0.063 \pm 0.015$ & $-0.35 \pm 0.06$ \\
\hline \multicolumn{6}{|l|}{ D. Bile acid-fed (3 days) } \\
\hline Control & 7 & $795 \pm 62$ & $+0.139 \pm 0.030$ & $-0.088 \pm 0.019$ & $-0.59 \pm 0.21$ \\
\hline Bile acid-fed & 13 & $197 \pm 34$ & $+0.127 \pm 0.005$ & $-0.105 \pm 0.020$ & $-0.92 \pm 0.12$ \\
\hline
\end{tabular}

These studies were performed essentially as described in the legend to Fig. 5. In groups A, B, and C animals with some form of interruption of the enterohepatic circulation of bile acids, i.e., biliary diversion for $48 \mathrm{~h}$, cholestyramine feeding for 7 days, or ileal resection for $3 \mathrm{mo}$, along with appropriate control animals were injected intravenously with a bolus of intestinal lipoproteins containing varying amounts of cholesterol at the mid-light phase of the light cycle and were then killed $12 \mathrm{~h}$ later at the mid-dark phase of the cycle. As illustrated in Fig. 5 for the case of cholestyramine feeding, three types of correlations were determined: column 3 gives the relationship of the hepatic cholesterol ester level to the amount of lipoprotein cholesterol injected: columns 4 and 5, respectively, give the relationship between the rate of cholesterol synthesis and the amount of cholesterol injected and the level of hepatic cholesterol esters. Column 2 gives the intercept of the linear regression curves on the $y$ axis and represents the rate of $\mathrm{C}_{2}$ flux into cholesterol by the liver when 0 chylomicron cholesterol was injected, i.e., when $x=0$. The last experiment (group D) shows similar data obtained in animals fed $0.5 \mathrm{~g}$ of taurocholate per $100 \mathrm{~g}$ of chow for 3 days before administration of the chylomicrons. The first column gives the number of animals used to construct each regression curve; all values represent the slopes of these curves, as determined by the method of least squares, \pm 1 SD of the slope.

(column 4) seen after administration of varying amounts of chylomicron cholesterol also were similar in the control rats and in the animals with one of these types of interruption of the enterohepatic circulation of bile acids. However, in that the average values for the rise in cholesterol esters were slightly higher while the fractional inhibition constants were slightly lower in the experimental groups when compared to the appropriate control values, the fractional inhibition of cholesterol synthesis expressed per milligram per gram rise in cholesterol esters was significantly lower (column 5) in the two groups of animals with more complete interruption of the enterohepatic circulation. Thus, in the animals with biliary diversion and ileal resection, the amount of inhibition manifest for an equal rise in the level of hepatic cholesterol esters was only half as great as seen in the control groups. In contrast, in animals fed bile acid to expand the bile acid pool the fractional inhibition constant was higher than in the appropriate control group (group D). These find- ings strongly suggest that the size of the bile acid pool effects the degree of inhibition of hepatic cholesterol synthesis produced by the entry of a given amount of cholesterol into the hepatocyte; when the liver is synthesizing bile acids at a high rate the entry of an amount of chylomicron cholesterol sufficient to raise the cholesterol ester content by $1 \mathrm{mg} / \mathrm{g}$ results in significantly less inhibition $(\cong-0.36)$ than when bile acid synthesis is suppressed by bile acid feeding $(-0.92)$.

\section{DISCUSSION}

Current data suggest that the rate of cholesterol synthesis in the liver is largely determined by a regulatory pool of intracellular sterol that responds to changes in both the rates of entry and exit of cholesterol from the hepatocyte. In animals on a low cholesterol diet, input of cholesterol into the liver cell occurs principally by uptake of low density lipoproteins, remnants of chylomicrons and very low density lipoproteins and, at 
much lower rates, high density lipoproteins $(34-37) .^{3}$ Under this circumstance net cholesterol input is relatively slow so that there is little accumulation of cholesterol esters (0.1-0.2 $\mathrm{mg} / \mathrm{g}$ ) and cholesterol synthesis occurs at a significant but intermediate rate. When there are increased needs for cholesterol by the body, e.g., when very low density lipoprotein synthesis is driven by uptake of fatty acids by the liver $(38,39)$ or when bile acid synthesis is increased by interruption of the enterohepatic circulation $(1,19,23,40,41)$, de novo cholesterol synthesis increases to meet the new demand(s). After the addition of cholesterol to the diet there is a marked increase in the entry of cholesterol from the intestine into the body carried in chylomicrons; these lipoproteins are partially metabolized by the action of lipoprotein lipase (42-44), and the resulting remnants are rapidly taken up into the liver by a high velocity, saturable transport system located on the sinusoidal membrane of the liver cell $(34,35)$. The rate of entry of these remnants is usually much higher than the rate at which the cholesterol can be disposed of so that much of the cholesterol that enters the cell is temporarily stored as cholesterol esters, and there is a reciprocal suppression of de novo cholesterol synthesis $(29,30,36)$. In this circumstance cholesterol absorbed from the intestine, rather than newly synthesized cholesterol, must become the major substrate for the sterol needs of the cell.

The data presented in the present studies are consistent with this model and provide the basis for six major conclusions concerning the interrelationships between the flow of bile acid and cholesterol through the intestine and liver and their respective functions in the regulation of hepatic cholesterol synthesis. First, it is well established that bile acids have an obligatory role in promoting the movement of cholesterol from the intestinal lumen into the intestinal lymph (45). These amphipaths, for example, are necessary for the emulsification and digestion of dietary cholesterol esters (46), for the movement of cholesterol across the intestinal unstirred water layers (47), and for the synthesis and (or) movement of chylomicrons into the intestinal lymph (48). Thus, under circumstances where the amount of cholesterol in the intestinal lumen is kept constant, the amount absorbed depends critically on the functional size of the bile acid pool.

Second, cholesterol movement into the liver cell, however, appears to be independent of the rate of bile acid flow into the hepatocyte. In studies performed in vivo in the rat, for example, the rate of uptake of chylomicron cholesterol and its deposition in the cholesterol ester pool of the liver is essentially constant under circumstances where the movement of bile acid through the cell is varied markedly by biliary diversion,

\footnotetext{
${ }^{3}$ Sherrill, B. C. Unpublished observations.
}

cholestyramine feeding, or obstruction of the common bile duct (36). Similar findings are seen in the present study where the level of cholesterol esters achieved 12 $\mathrm{h}$ after the administration of chylomicrons is the same in control rats and animals with manipulation of the enterohepatic circulation of bile acid (Table VI). Further direct support for this conclusion comes from recent studies in the isolated perfused liver where it has been shown that chylomicron remnants are taken up intact by a saturable transport system the velocity of which is independent of the integrity of the enterohepatic circulation of bile acids (35). ${ }^{3}$ Thus, in contrast to the situation in the intestine, the rate of movement of cholesterol into the liver cell (carried in the chylomicron remnant) is independent of the rate of flow of bile acid through the hepatocyte.

Third, the present studies provide unequivocal evidence that most of the suppressive effect of bile acid feeding on the rate of hepatic cholesterol synthesis is mediated through enhanced absorption of cholesterol present in the intestinal lumen. This is best seen in those experiments shown in Fig. 4 where the degree of inhibition of hepatic cholesterol synthesis and the level of hepatic cholesterol esters produced by expansion of the bile acid pool is directly related to the amount of cholesterol available in the intestine for potential absorption. Furthermore, partially blocking cholesterol movement from the intestine to the liver either by feeding $\beta$-sitosterol (Table III) or by diverting the intestinal lymphatic outflow (Table II) greatly reduces the inhibitory effects of bile acid feeding on the rate of cholesterol synthesis in the liver. Other reported data indicate that variations in the inhibitory capacity of different bile acids also can be largely attributed to the different capacities of these various bile acids to enhance cholesterol absorption. In the rat, for example, cholic acid feeding results in a greater increase in absorption of dietary cholesterol (49) and more marked suppression of hepatic cholesterol synthesis (22) than does the feeding of chenic acid. Thus, these various observations support the view that most of the observed suppression of cholesterol synthesis associated with expansion of the bile acid pool is mediated through increased cholesterol absorption and inhibition of hepatic cholesterol synthesis by cholesterol reaching the liver in chylomicron remnants.

Fourth, the present studies also indicate that bile acids have no direct regulatory effect within the liver cell on HMG CoA reductase. The most recent support for this concept, based upon studies where bile acid was fed to animals with intestinal lymphatic diversion (24), seems refuted by the experimental results reported in Table IV demonstrating that even the small amount of residual suppression of hepatic cholesterol synthesis that is associated with a fivefold increase in the size of the taurocholate pool in such animals can 
be attributed to cholesterol absorbed through collateral lymphatic vessels and (or) to partial fasting. Furthermore, under circumstances where both dietary and biliary cholesterol are eliminated from the gastrointestinal tract, the movement of even greater than normal amounts of taurocholate or taurochenate through the liver has no demonstrable effect on the rate of hepatic cholesterol synthesis (Table V). In similar studies using the isolated perfused liver where the input of cholesterol carried in chylomicrons can be totally eliminated, the presence of bile acids in the perfusing media also has no demonstrable suppressive effect upon the rate of hepatic cholesterol synthesis (50-52) even though synthesis in such preparations can be inhibited by the presence of chylomicron remnants (53). Thus, taken together, these various observations provide strong support for our original contention that bile acids are not direct effectors of HMG CoA reductase within the liver cell (23).

Fifth, other evidence presented in these studies, however, demonstrates that bile acids do have an intrahepatic effect that indirectly alters the rate of hepatic cholesterol synthesis. This effect derives from the fact that the size of the bile acid pool alters the amount of cholesterol that is converted to bile acid and so is ultimately removed from the liver. Under circumstances where there is accelerated bile acid synthesis, e.g., with biliary diversion, the entrance of a given amount of cholesterol into the cell results in a fractional decrease in hepatic cholesterol synthesis of only about 0.36 per milligrams per gram rise in cholesterol esters, whereas, when bile acid synthesis is suppressed by bile acid feeding, the entrance of an identical amount of chylomicron cholesterol has a nearly threefold greater inhibitory capacity (Table IV). This same phenomenon is seen when the inhibition produced by bile acid feeding is compared to that produced by cholesterol feeding (Fig. 3); again the fractional inhibition is much greater per milligram per gram rise in hepatic cholesterol esters with bile acid feeding $(-3.04)$, where bile acid synthesis is suppressed, than with cholesterol feeding $(-1.04)$, where bile acid synthesis is either unchanged or actually increased (54). These various studies suggest that variation in the outflow of cholesterol from the hepatocyte as substrate for bile acid synthesis can alter the rate of hepatic cholesterol synthesis under circumstances where the entry of cholesterol into the cell is kept constant. Thus, bile acids have an intrahepatic effect in altering the rate of cholesterol synthesis to the extent that changes in the size of the bile acid pool alter the rate of bile acid production; this effect is in addition to the profound influence of the size of the bile acid pool in regulating the amount of cholesterol absorbed from the gastrointestinal tract and delivered to the liver in chylomicrons.

Finally, there is one other pathway in which choles- terol movement is coupled to bile acid transport. In a number of species it has been shown that the secretion of cholesterol into the bile is coupled in some manner to the rate of bile acid secretion $(55,56)$. Although the mechanism responsible for this association is not well understood, it is apparent that this is yet another pathway where changes in the bile acid pool can alter the rate of net removal of cholesterol from the liver cell.

In summary, the various specific mechanisms of interaction between bile acid and cholesterol in regulating cholesterol synthesis in the liver identified in this study readily account for many of the changes in sterol balance in different animal species and in man that occur with manipulations of the enterohepatic circulation. Bile acid feeding suppresses hepatic cholesterol synthesis to the extent necessary to compensate for both the decreased outflow of sterol to bile acids and the increased inflow of cholesterol to the liver from the intestine. If this compensatory suppression is adequate to offset the changes in cholesterol flow through the liver, then the serum cholesterol level and the body cholesterol pools remain unchanged $(57,58)$. If the increase in absorption is greater than can be compensated for by suppression of hepatic cholesterol synthesis, then serum cholesterol levels increase and body pools presumably expand. Conversely, after partial interruption of the enterohepatic circulation there is increased loss of cholesterol from the liver as substrate for bile acid production. However, if the increase in synthesis of bile acid fully compensates for the increased loss of acidic sterols in the feces, then there is enhanced hepatic cholesterol synthesis without a demonstrable alteration in the rate of cholesterol absorption. This situation has been reported in the baboon subjected to partial ileal resection (25). More commonly, however, cholestyramine feeding or ileal resection results in a much greater interruption of the enterohepatic circulation leading both to a decrease in the rate of cholesterol absorption and to accelerated loss of sterol from the liver during the synthesis of bile acids. This combined effect probably accounts for the marked increase in hepatic cholesterol synthesis seen in studies such as those illustrated by the data in Fig. 5 and in Table VI and in similar studies reported in man (59). Finally, it is of interest that, in patients with homozygous familial hypercholesterolemia, interruption of the enterohepatic circulation by cholestyramine feeding, ileal resection, or external biliary diversion is associated with the same marked compensatory increase in endogenous cholesterol synthesis as is seen in animals or in normal man (59-64) and suggests that the chylomicron-bile acid regulatory mechanisms described in this paper are intact and operative in these subjects who are known to have a defect in the regulation of cholesterol synthesis in peripheral tissues by circulating low density lipoproteins $(65,66)$. 


\section{ACKNOWLEDGMENTS}

The authors wish to acknowledge the excellent technical assistance of Joyce Eckles and Dorothy Lu and to thank Nancy Mandell for her help in the preparation of the manuscript.

This work was supported by U. S. Public Health Service research grants HL 09610, AM 16386, and AM 19329.

\section{REFERENCES}

1. Andersen, J. M., and J. M. Dietschy. 1977. Regulation of sterol synthesis in 15 tissues of rat. II. Role of rat and human high and low density plasma lipoproteins and of rat chylomicron remnants. J. Biol. Chem. 252: 3652-3659.

2. Ho, Y. K., J. R. Faust, D. W. Bilheimer, M. S. Brown, and J. L. Goldstein. 1977. Regulation of cholesterol synthesis by low density lipoprotein in isolated human lymphocytes. J. Exp. Med. 145: 1531-1549.

3. Brown, M. S., S. E. Dana, and J. L. Goldstein. 1974. Regulation of 3-hydroxy-3-methylglutaryl coenzyme A reductase activity in cultured human fibroblasts. J. Biol. Chem. 249: 789-796.

4. Andersen, J. M., and J. M. Dietschy. 1976. Regulation of sterol synthesis in adrenal gland of the rat by both high and low density human plasma lipoproteins. Biochem. Biophys. Res. Commun. 72: 880-885.

5. Gwynne, J. T., D. Mahafee, H. B. Brewer, Jr., and R. L. Ney. 1976. Adrenal cholesterol uptake from plasma lipoproteins: regulation by corticotropin. Proc. Natl. Acad. Sci. U.S.A. 73: 4329-4333.

6. Gould, R. G. 1951. Lipid metabolism and atherosclerosis. Am. J. Med. 11: 209-227.

7. Gould, R. G., C. B. Taylor, J. S. Hagerman, I. Warner, and D. J. Campbell. 1953. Cholesterol metabolism. I. Effect of dietary cholesterol on the synthesis of cholesterol in dog tissue in vitro. J. Biol. Chem. 201: 519-528.

8. Dietschy, J. M., and M. D. Siperstein. 1967. Effect of cholesterol feeding and fasting on sterol synthesis in seventeen tissues of the rat. J. Lipid Res. 8: 97-104.

9. Dietschy, J. M., and J. D. Wilson. 1968. Cholesterol synthesis in the squirrel monkey: relative rates of synthesis in various tissues and mechanisms of control. J. Clin. Invest. 47: 166-174.

10. Dietschy, J. M., and M. D. Siperstein. 1965. Cholesterol synthesis by the gastrointestinal tract: localization and mechanisms of control. J. Clin. Invest. 44: 1311-1327.

11. Dietschy, J. M. 1968. The role of bile salts in controlling the rate of intestinal cholesterogenesis. J. Clin. Invest. 47: 286-300.

12. Dietschy, J. M., and W. G. Gamel. 1971. Cholesterol synthesis in the intestine in man: regional differences and control mechanisms. J. Clin. Invest. 50: 872-880.

13. Friedman, M., S. O. Byers, and F. Michaelis. 1951. Production and excretion of cholesterol in mammals. IV. Role of liver in restoration of plasma cholesterol after experimentally induced hypocholesteremia. Am.J. Physiol. 164: 789-791.

14. Eckles, N. E., C. B. Taylor, D. J. Campbell, and R. G. Gould. 1955. The origin of plasma cholesterol and the rates of equilibration of liver, plasma, and erythrocyte cholesterol. J. Lab. Clin. Med. 46: 359-371.

15. Lindsey, C. A., Jr., and J. D. Wilson. 1965. Evidence for a contribution by the intestinal wall to the serum cholesterol of the rat. J. Lipid Res. 6: 173-181.

16. Wilson, J. D. 1968. Biosynthetic origin of serum cholesterol in the squirrel monkey: evidence for a contribution by the intestinal wall. J. Clin. Invest. 47: 175-187.
17. Wilson, J. D., C. A. Lindsey, and J. M. Dietschy. 1968. Influence of dietary cholesterol on cholesterol metabolism. Ann. N. Y. Acad. Sci. 149: 808-821.

18. Dietschy, J. M., and J. D. Wilson. 1970. Regulation of cholesterol metabolism. N. Engl.J. Med. 282: 1128-1138, 1179-1183, 1241-1249.

19. Weis, H. J., and J. M. Dietschy. 1975. The interaction of various control mechanisms in determining the rate of hepatic cholesterogenesis in the rat. Biochim. Biophys. Acta. 398: 315-324.

20. Shefer, S., S. Hauser, V. Lapar, and E. H. Mosbach. 1973. Regulatory effects of sterols and bile acids on hepatic 3-hydroxy-3-methylglutaryl CoA reductase and cholesterol $7 \alpha$-hydroxylase in the rat. J. Lipid Res. 14: 573-580.

21. Shefer, S., G. Salen, T. Fedorowski, H. Dyrszka, and E. H Mosbach. 1975. Inhibition of cholesterol biosynthesis by chenodeoxycholic acid in the rhesus monkey. J. Steroid Biochem. 6: 1563-1564.

22. Carrella, M., and J. M. Dietschy. 1977. Comparison of the effects of cholic acid and chenic acid feeding on rates of cholesterol synthesis in the liver of the rat. Am.J.Dig. Dis. 22: 318-326.

23. Weis, H. J., and J. M. Dietschy. 1969. Failure of bile acids to control hepatic cholesterogenesis: evidence for endogenous cholesterol feedback. J. Clin. Invest. 48: 23982408.

24. Hamprecht, B., R. Roscher, G. Waltinger, and C. Nussler. 1971. Influence of bile acids on the activity of rat liver 3-hydroxy-3-methylglutaryl coenzyme A reductase. 2. Effect of cholic acid in lymph fistula rats. Eur. J. Biochem. 18: $15-19$

25. Wilson, J. D. 1972. The relation between cholesterol absorption and cholesterol synthesis in the baboon. J. Clin. Invest. 51: 1450-1458.

26. Thistle, J. L., and A. F. Hofmann. 1973. Efficacy and specificity of chenodeoxycholic acid therapy for dissolving gallstones. N. Engl. J. Med. 289: 655-659.

27. LaRusso, H. F., N. E. Hoffman, A. F. Hofmann, T. C. Northfield, and J. L. Thistle. 1975. Effect of primary bile acid ingestion on bile acid metabolism and biliary lipid secretion in gallstone patients. Gastroenterology. 69: 1301-1314.

28. Weis, H. J., and J. M. Dietschy. 1974. Adaptive responses in hepatic and intestinal cholesterogenesis following ileal resection in the rat. Eur. J. Clin. Invest. 4: 33-41.

29. Nervi, F. O., H. J. Weis, and J. M. Dietschy. 1975. The kinetic characteristics of inhibition of hepatic cholesterogenesis by lipoproteins of intestinal origin. J. Biol. Chem. 250: $4145-4151$

30. Nervi, F. O., and J. M. Dietschy. 1975. Ability of six different lipoprotein fractions to regulate the rate of hepatic cholesterogenesis in vivo. J. Biol. Chem. 250: 8704-8711.

31. Dietschy, J. M., and J. D. McGarry. 1974. Limitations of acetate as a substrate for measuring cholesterol synthesis in liver. J. Biol. Chem. 249: 52-58.

32. Eriksson, S. 1960. Bile acid pool in the rat. Acta Physiol. Scand. 48: 439-442.

33. Gould, R. G., and E. A. Swyryd. 1966. Sites of control of hepatic cholesterol biosynthesis. J. Lipid Res. 7: 698707.

34. Sherrill, B. C., and J. M. Dietschy. 1976. Uptake of lipoproteins of intestinal origin in the isolated perfused liver. Circulation II. 54: 91. (Abstr.)

35. Sherrill, B. C., and J. M. Dietschy. 1977. Characterization of the sinusoidal transport process responsible for uptake of chylomicrons by the liver. J. Biol. Chem. In press

36. Andersen, J. M., F. O. Nervi, and J. M. Dietschy. 1977. Rate constants for the uptake of cholesterol from various 
intestinal and serum lipoprotein fractions by the liver of the rat in vivo. Biochim. Biophys. Acta. 486: 298-307.

37. Faergeman, O., and R. J. Havel. 1975. Metabolism of cholesteryl esters of rat very low density lipoproteins.J. Clin. Invest. 55: 1210-1218.

38. Goh, E. H., and M. Heimberg. 1973. Stimulation of hepatic cholesterol biosynthesis by oleic acid. Biochem. Biophys. Res. Commun. 55: 382-388.

39. Goh, E. H., and M. Heimberg. 1977. Effect of free fatty acids on activity of hepatic microsomal 3-hydroxy-3methylglutaryl coenzyme A reductase and on secretion of triglyceride and cholesterol by liver. J. Biol. Chem. 252: $2822-2826$.

40. Myant, N. B., and H. A. Eder. 1961. The effect of biliary drainage upon the synthesis of cholesterol in the liver. J. Lipid Res. 2: 363-368.

41. Economou, S. G., B. J. Tews, C. B. Taylor, and G. E. Cox. 1958. Studies on lipid metabolism in dogs with altered biliary physiology. Surg. Forum. 8: 218-221.

42. Redgrave, T. G. 1970. Formation of cholesteryl ester-rich particulate lipid during metabolism of chylomicrons. $J$. Clin. Invest. 49: 465-471.

43. Higgins, J. M., and C. J. Fielding. 1975. Lipoprotein lipase. Mechanism of formation of triglyceride-rich remnant particles from very low density lipoproteins and chylomicrons. Biochemistry. 14: 2288-2292.

44. Fielding, C. J., and P. E. Fielding. 1976. Chylomicron protein content and the rate of lipoprotein lipase activity. J. Lipid Res. 17: 419-423.

45. Siperstein, M. D., I. L. Chaikoff, and W. O. Reinhardt. 1952. $\mathrm{C}^{14}$-cholesterol. V. Obligatory function of bile in intestinal absorption of cholesterol.J. Biol. Chem. 198: 111114.

46. Treadwell, C. R., and G. V. Vahouny. 1968. Cholesterol absorption. Handb. Physiol. 3(Sect. 6. Alimentary Canal): $1407-1438$.

47. Westergaard, H., and J. M. Dietschy. 1976. The mechanism whereby bile acid micelles increase the rate of fatty acid and cholesterol uptake into the intestinal mucosal cell. J. Clin. Invest. 58: 97-108.

48. Wilson, J. D., and R. T. Reinke. 1968. Transfer of locally synthesized cholesterol from intestinal wall to intestinal lymph. J. Lipid. Res. 9: 85-92.

49. Cohen, B. I., R. F. Raicht, and E. H. Mosbach. 1977. Sterol metabolism studies in the rat. Effects of primary bile acids (sodium taurochenodeoxycholate and sodium taurocholate) on sterol metabolism.J. Lipid. Res. 18: 223231.

50. Liersch, M. E. A., C. A. Barth, H. J. Hackenschmidt, H. L. Ullmann, and K. F. A. Decker. 1973. Influence of bile salts on cholesterol synthesis in the isolated perfused rat liver. Eur. J. Biochem. 32: 365-371.

51. Liersch, M. C. Barth, J. Hackenschmidt, H. Ullmann, and K. Decker. 1972. In Bile Acids in Human Disease. P. Back and W. Gerak, editors. Friedrich-Karl Schattauer-Verlag, Stuttgart, Germany. p. 113.
52. Cooper, A. D. 1976. The regulation of 3-hydroxy-3methylglutaryl coenzyme A reductase in the isolated perfused rat liver. J. Clin. Invest. 57: 1461-1470.

53. Cooper, A., and A. Garst. 1976. Regulation of hepatic cholesterol (CHOL) synthesis by chylomicron remnants (CR). Gastroenterology. 70: 873. (Abstr.)

54. Wilson, J. D. 1964. The quantification of cholesterol excretion and degradation in the isotopic steady state in the rat: the influence of dietary cholesterol. J. Lipid Res. 5: 409-417.

55. Wheeler, H. O., and K. K. King. 1972. Biliary excretion of lecithin and cholesterol in the dog. J. Clin. Invest. 51: $1337-1350$.

56. Hardison, W. G. M., and J. T. Apter. 1972. Micellar theory of biliary cholesterol excretion. Am. J. Physiol. 222: 6167.

57. Hoffman, N. E., A. F. Hofmann, and J. L. Thistle. 1974. Effect of bile acid feeding on cholesterol metabolism in gallstone patients. Mayo Clin. Proc. 49: 236-239.

58. Webster, K. H., M. C. Lancaster, A. F. Hofmann, D. F. Wease, and A. H. Baggenstoss. 1975. Influence of primary bile acid feeding on cholesterol metabolism and hepatic function in the rhesus monkey. Mayo Clin. Proc. 50: 134138.

59. Grundy, S. M., E. H. Ahrens, Jr., and G. Salen. 1971. Interruption of the enterohepatic circulation of bile acids in man: comparative effects of cholestyramine and ileal exclusion on cholesterol metabolism.J. Lab. Clin. Med. 78: 94-121.

60. Davis, J. A., I. D. A. Johston, C. D. Moutafis, and N. B. Myant. 1966. Ileal bypass in hypercholesterolemia. Lancet. II: 971-972.

61. Johnston, I. D. A., J. A. Davis, C. D. Moutafis, and N. B. Myant. 1967. Ileal bypass in the management of familial hypercholesterolemia. Proc. R. Soc. Med. 60: 16-18.

62. Moutafis, C. D., and N. B. Myant. 1968. Increased hepatic synthesis of cholesterol after ileal bypass in monkeys. Clin. Sci. (Oxf.). 34: 541-548.

63. Moutafis, C. D., N. B. Myant, and S. Tabaqchali. 1968. The metabolism of cholesterol after resection or bypass of the lower small intestine. Clin. Sci. (Oxf.). 35: 537-545.

64. Deckelbaum, R. J., R. S. Lees, D. M. Small, S. E. Hedberg, and S. M. Grundy. 1977. Failure of complete bile diversion and oral bile acid therapy in the treatment of homozygous familial hypercholesterolemia. N. Engl. J. Med. 296: 465-470.

65. Brown, M. S., S. E. Dana, and J. L. Goldstein. 1973. Regulation of 3-hydroxy-3-methylglutaryl coenzyme A reductase activity in human fibroblasts by lipoproteins. Proc. Natl. Acad. Sci. U.S.A. 70: 2162-2166.

66. Brown, M. S., and J. L. Goldstein. 1974. Familial hypercholesterolemia: defective binding of lipoproteins to cultured fibroblasts associated with impaired regulation of 3-hydroxy-3-methylglutaryl coenzyme A reductase activity. Proc. Natl. Acad. Sci. U.S.A. 71: 788-792. 